\title{
Entre contener y ser contenido
}

\section{Resumen}

El presente artículo propone una nueva manera de entender los elementos comunes en la formación y el hacer del diseño y de la arquitectura, posibilitando un pensar común y un coactuar en diversas escalas de intervención, necesarias para el manejo de la complejidad del paisaje contemporáneo.

La convicción de un pensar común entre ambas disciplinas permite explorar un marco filosófico que incluye a pensadores tan trascendentales como Aristóteles, Kant y Heidegger, estableciendo un orden de pensamiento que los relaciona y sitúa.

En momentos en que el territorio está siendo visible y negativamente afectado por elementos no pensados o que fueron imaginados separadamente, este artículo propone una mirada que le dé sentido de totalidad a las acciones del diseño y de la arquitectura, como elementos que permanentemente se contienen en otros de diferente escala, pero que siempre están vinculados.

Reconocer el paisaje físico y mental, tangible e intangible que contiene al diseño y a la arquitectura contribuirá a establecer un marco de acción donde todos los elementos construidos por el ser humano puedan tener un rol específico y una escala asumida, e intercomprenderse para mejor utilización de los recursos, disminuir el impacto ambiental y contribuir a un orden social mejor interpretado por los objetos, espacios y sus representaciones.

El diseño y la arquitectura deben ser concebidos como disciplinas que vuelven a quedar englobadas en un accionar común, luego de largas décadas en que la especificidad tendía a buscar caminos disciplinarios divergentes o roles profesionales exclusivos. Esto se observa desde el Manifiesto Suprematista de Malevich ${ }^{\left({ }^{(1)}\right.}$ que declaraba que el arte había avanzado para crear en el espacio o la definición de arqui- 
tectura como Inmovilidad Substancial de Borchers ${ }^{(2)}$ en el que el suelo es el primer material, hasta el Programa para una arquitectura móvil del Grupo GEAM ${ }^{(3)}$ en 1960, en el cual se reconocen aspectos emergentes de la ciudad como la movilidad, las interconexiones y la comunicación, que deben ser tratados con urgencia ante el explosivo desarrollo de las grandes conurbaciones actuales.

Esta redefinición de un accionar convergente entre diseño y arquitectura permite volver a lo elemental, pero poniendo atención sobre lo que vincula a los diferentes elementos de su cultura, y no a lo que los distingue. Por lo tanto es una mirada interesada en los ámbitos convergentes o superpuestos entre lo que estas dos disciplinas tienen de arte, técnica, ciencia o filosofía, más que en su propia especificidad. Es una invitación a volver a observar al ser humano como constructor de un medio ambiente donde imágenes, objetos, espacios y paisajes interactúan de forma compleja y esencial, y en donde sigue inventando sus herramientas, sus espacios, su entorno, para comprender que luego este entorno va transformándolo, constituyendo un ser que se puede identificar y comprender a través de sus obras tangibles e intangibles.

Por otro lado, hablar de diseño y arquitectura como disciplinas nos lleva a un campo contextual en el cual se han separado de forma forzada oficios que antiguamente se presentaban reunidos. Históricamente, al igual que pasó con la ingeniería o la construcción, el diseño era entendido dentro de los oficios de la arquitectura. Entonces desde un punto de vista histórico es reconocible la matriz metodológica que nace de la arquitectura y que se ha separado en carreras diferentes, solo con fines prácticos o del mercado profesional, por así decirlo.

Este fenómeno no ha sido igual en todas partes, pues en algunas culturas como la inglesa, el diseño es el hacer que engloba todas las disciplinas visuales, incluyendo a la arquitectura, y nadie siente menoscabada su capacidad técnica. En los medios sajones, por otra parte, son las ingenierías las que incluyen disciplinas como el diseño y la arquitectura y nadie siente menoscabada su creatividad. Por lo tanto se trata de una separación práctica, contextual, local, mas no esencial al arte, al diseño o a la arquitectura.

Cuando hablamos de arquitectura y diseño de forma genérica estamos refiriéndonos a variados significados. Se ha llevado la arquitectura a la informática, a la biología y hasta la literatura, como un orden subyacente, no siempre evidente, pero que le da ser y sentido a algo, es decir, identidad. Por otra parte, el diseño dice relación con la forma en que las cosas aparecen, su constitución visible y perceptible, que es una segunda manifestación de un orden, el diseño es genéricamente el resultado perceptible de una esencia intangible.

El pensamiento contemporáneo ha demostrado que ambas concepciones generales de la arquitectura y el diseño tienen un alto grado de abstracción, pues orden y forma son una elaboración cultural, es decir, ambas existen y son visibles para una mente que ya ha sido capaz de pensarlas. La arquitectura como orden y el diseño como forma solo son visibles para una mente entrenada y alerta, de otro modo simplemente pasan por delante de nuestros ojos sin que los veamos.

Esto es lo que explica por qué algunas obras claves simplemente son ignoradas, no reconocidas o perdidas entre otras tantas obras mediocres y sin importancia. Saber observar no es solo un acto de los órganos de la percepción, sino sobre todo una función mental de dar sentido a lo que aparece.

Todos recordamos la escena del film "200I Odisea del Espacio"(4), con el primate usando el hueso de una quijada para imponerse y aniquilar a sus iguales, porque mostró de forma inigualable la potencia del homo sapiens para valerse de elementos más allá de su cuerpo, consiguiendo resultados que con sus propios medios eran impensables. Las herramientas fueron el primer diseño, apropiado y luego muy elaborado, para cortar, cazar, defenderse, abrigarse, etc. Abrirse camino en un mundo hostil era el problema, y el homo sapiens lo consiguió proyectando elementos que superaban su cuerpo, es decir, construyendo proyecciones de su cuerpo en función de lo que observaba de la naturaleza y de su entorno. Multiplicar la escasa fuerza, potenciar los cortes, ablandar las comidas, reforzar sus pies con calzados para condiciones extremas, mejorar su alcance, su velocidad, etc.

La mirada no debe ser puesta solamente en el objeto, también debe notarse el grupo de individuos, sus relaciones de poder, el espacio en que esto se da y las circunstancias de su uso, es decir, el observar las acciones de protegerse y potenciar su cuerpo llevaron al ser humano a representar las fuerzas naturales, a representarse a sí mismo, y finalmente a representar un paisaje, físico social o imaginario. La escena de la película de Stanley Kubrick no es esencialmente diferente para un grupo de jóvenes hoy, utilizando un teléfono inteligente o mostrando su nueva casa.

Ya lo expresaba Aristóteles, que estamos inmersos en un mundo de cosas manufacturadas ${ }^{(5)}$, en el cual vamos descubriendo sus cualidades y relaciones. Estas cosas o sustancias primeras son constituidas por la materia y la forma, causas indivisibles e inseparables, que las determinan conjuntamente a ser algo real, son sus principios internos, principios visibles de algo que es invisible. La materia es el principio de todo cambio o transformación ${ }^{(6)}$, pues se degrada o descompone, 
no así la forma que es el principio de estabilidad y determinación. Además Aristóteles señala la imposibilidad de pensar en la existencia de las cosas fuera de un lugar. Las cosas dependen del espacio, que "necesariamente es primero en el orden de las potencias, y fundamento de todas las cosas" (7).

Ahora bien, materia y forma llegan a ser porque existe un agente o causa eficiente, que es el diseñador-constructor, para que una materia tome forma y se constituya en objeto. Causa que es de un orden diferente al natural, el cual solamente puede reproducirse a sí mismo. Sin embargo, para Aristóteles es la causa final la que lleva al agente a manufacturar una cosa y la que pone en acción las otras causas, señala que "la causa final es el bien de la cosa".

“...Todos concuerdan que en la sabiduría, propiamente dicha, concierne a las primeras causas y primeros principios. Y si, como se dijo, el empírico parece más sabio del que tiene de los entes puras sensaciones; y más sabio que el empírico parece el que posee el arte -y el técnico más que el artesano- ¡cuánto no será superior la ciencia puramente especulativa a la que tiene por fin la producción!” (Aristóteles, 1980a).

Martin Heidegger en la Pregunta por la Técnica rescata que estas cuatro causas, según el pensamiento griego, más bien corresponden a "modos de ser-responsable-de" y enfatiza que entre ellas "se copertenecen entre si” ${ }^{(8)}$, agradeciendo -a propósito del famoso ejemplo de la copa sacrificial de plata- al orfebre por haber sido responsable de reunir, poner en juego y hacer aparecer. A esto Martin Heidegger lo denomina el dar-lugar-a como la esencia que se hace presente, pues sin la copa no se hacía presente el sacrificio. Martin Heidegger afirma que la copa trae a presencia el sacrificio, esto es, el legítimo producir, el desocultar de la técnica. Agrega, además, que todo producir se funda en el desocultar, por lo tanto la técnica no es un simple medio, es un modo de la verdad. En "Construir, Habitar, Pensar" (9), Martin Heidegger despliega sus célebres ejemplos del puente como lugar y de la casa de un feudo en la Selva Negra alemana, en los cuales extiende el construir al habitar como esencia del ser humano, visible en estos objetos, pues se construye por el habitar y se piensa para el habitar. Martin Heidegger resume las cuatro causas aristotélicas en un doble resultado del habitar: el traer a presencia la Tierra y el hacer aparecer un mundo, aludiendo al necesario vínculo del hacer con y trasformar la naturaleza, y al resultado de la cultura que construye el mundo del ser humano.

"Construir y pensar, según sus clases respectivas, son indispensa-

bles para el habitar. Pero ambos son también insuficientes para el habitar, mientras impulsen lo de cada uno aisladamente, en lugar de oírse mutuamente. Tendrían este poder, si ambos, construir y pensar, que pertenecen al habitar, quedan en sus límites y saben que tanto el uno como el otro vienen del taller de una larga experiencia e incesante ejercitación. (Heidegger, 1951(10)).

Immanuel Kant, por su parte, si bien cronológicamente es anterior a Martin Heidegger, en su "Crítica del Juicio"(II) retoma el pensamiento aristotélico y separa definitivamente la naturaleza del arte, como actividad que expresa la naturaleza ${ }^{(12)}$, pero no es naturaleza, pues la supera por el ideal, como perfección pensada y luego puesta en obra. Es Immanuel Kant quien propone un sistema de la cultura basado en la experiencia, producto de dos factores: los sentidos y el entendimiento, donde los sentidos son la primera función que luego es abstraída por el entendimiento, el cual unifica lo que en la intuición se da de forma múltiple. La cultura para Immanuel Kant se extiende en tres ámbitos: en la realización de la libertad, en la conquista de la naturaleza y también en el mundo del arte y la belleza, que recrea a los dos anteriores, posibilitando una tercera esfera de la cultura.

Esta nueva esfera de la cultura que se da con los juicios estéticos, establece un vínculo entre la representación y el estado sentimental del observador, y "tiene pretensiones de universalidad". La clave está en determinar el sentimiento estético como una relación entre facultades de representación, pues desarrollan un juego libre ${ }^{\left({ }_{13}\right)}$ y deben ser universalmente comunicables.

Entonces el juicio estético es concebido por Kant como una nueva dirección de la conciencia y por lo tanto de la cultura, pero que no puede tener otro contenido diferente a las leyes naturales o las leyes morales, su valor está en cotejar los juicios propios con los de los demás, los reales y los posibles, constituyendo lo que nos permite pensar y desarrollarnos.

"La naturaleza, pues, funda su conformidad con leyes en principios a priori del entendimiento, como facultad de conocer; el arte se rige en su finalidad a priori según el Juicio en relación con el sentimiento de placer y dolor; finalmente, las costumbres (como producto de la libertad) están bajo la idea de una forma semejante de la finalidad, que se cualifica para leyes universales como un motivo de determinación de la razón en consideración de la facultad de desear".

(Kant, 1876) ${ }^{(14)}$.

Lo que comparten el diseño y la arquitectura es la necesidad de representar y comunicar el mundo para reconstruirlo, del modo en que hemos explicado anteriormente. Esto está reunido por la visión holística contemporánea: donde todo está contenido y a la vez contiene al tanto de orden tangible como intangible.

El Paisaje, como intelección del territorio, es el nuevo paradigma 
que envuelve nuestro hacer, desde el ámbito de un microchip hasta los elementos que contribuyen al calentamiento global. Cada decisión del ser humano de transformar su medio está hoy inserta en una escala de intervención que afecta a otros ámbitos, que son contenidos o son continentes.

Ambas disciplinas comparten que el mundo del ser humano es una representación cultural, con base en lo mental, como actividad esencial y centrada en el ser humano, donde toda representación es un camino de búsqueda de una verdad a construir para su visualización y existencia, incluso más allá del uso y el valor. Lo mental, por su parte, es una actividad individual que crece y se alimenta de lo colectivo, es decir, la interacción es el nuevo paradigma del diseñador y del arquitecto, por cuanto debe insertar su hacer en un medio concreto, pero lleno de aspiraciones y responsabilidades. Lo mental colectivo abre espacios para encontrar nuevos caminos de desarrollo y la intersubjetividad son los espacios ganados para compartir sin coacción ni imposiciones sociales ni económicas.

Esto es solo si asumimos que hoy hay conciencia de que el construir del ser humano se va diferenciando cada vez más de la naturaleza, es decir, ya está asumido que el futuro es sin volver atrás.

El camino de este artículo presenta que la disciplina del hacer no tiene sentido sin la disciplina del pensar, camino común al diseño y a la arquitectura y clave de la enseñanza universitaria: formar una disciplina mental que reflexione sobre las cosas, sobre los procesos, sobre los sujetos y sobre sí misma, para dotar de sentido las obras que surgen de este proceso. Dotar de sentido es el llamado al ámbito universitario de la profesión.

El diseño y la arquitectura continuarán siendo espacios de experiencias sensibles, y no dejarán de tener el rol de articulación sistémica entre naturaleza y cultura; sin embargo, la responsabilidad del diseñador y del arquitecto es asumir su estar contenido o su contener diferentes escalas de intervención intervinculadas, donde unas se afectan y dependen de las otras. No reconocerlo es apostar a un mundo parcial, fragmentado, disperso e irresponsable que debe quedar atrás. El diseño y la arquitectura hoy deben asumir el contener y el ser contenidos, ese es el nuevo contexto de todo proyecto.
Notas

1. Kasimir Malevich publicó en 1924 su Manifiesto Suprematista, al que llamó "Unovis: el establecimiento de nuevas formas de arte", donde señalaba que la pintura, como arte del presente, había sobrepasado la superficie plana y había avanzado hacia el arte de crear en el espacio. En Ulrich Conrads, "Programs and Manifestoes on 20th-century architecture". MIT Press, Cambridge, Massachusetts, 1970. Pág. 87.

2. Rafael Moneo expresaba su impresión porque Juan Borchers definía la arquitectura como "el lenguaje de la inmovilidad substancial" refiriéndose a un concepto de lugar en el cual el suelo es el primer material de construcción, que es inamovible y en el cual la obra echa raíces, luego el suelo "garantiza su condición de objeto". En Revista CA N98, Julio/agosto/septiembre 1999, Contraportada. Resumen de "Inmovilidad substancial. Contra la indiferencia como norma". Rafael Moneo Arquitecto. Anyway. Ediciones ARQ. Escuela de Arquitectura. Pontificia Universidad Católica de Chile. Editorial Universitaria. Santiago de Chile, 1995.

3. GEAM es el Groupe d'études d'architecture mobile, formado por jóvenes arquitectos franceses, holandeses, polacos e israelíes, en 1956, en el último encuentro de los CIAM antes de su disolución definitiva.

4. Film dirigido, producido y cuyo guión fue hecho por Stanley Kubrick fue estrenado en 1968.

5. Cabe señalar que Aristóteles llama sustancias primeras a los individuos que son por naturaleza y no por arte, aunque ejemplifica con las estatuas, la carpintería, etc.

6. Aristóteles, Física. Editorial Belles Lettres, Paris, 193, a., citado en Giannini, Humberto, "Breve historia de la Filosofía", Editorial Universitaria, Santiago, 1977, págs. 65 a 67.

7. Aristóteles, Física. Editorial Belles Lettres, Paris, 209, a., citado en Giannini, Humberto, "Breve historia de la Filosofía", Editorial Universitaria, Santiago, 1977, pág. 69.

8. Heidegger, Martin. La Pregunta por la Técnica. En Ciencia y Técnica. Editorial Universitaria, Santiago, 1993. Págs. 76 a 81.

9. En Ciencia y Técnica. Editorial Universitaria, Santiago, 1993. Pág. 178.

10. Heidegger, Martin. Construir, Habitar, Pensar. En Ciencia y Técnica. Editorial Universitaria, Santiago, 1993. Pág. 178.

11. Publicada originalmente en 1790 , traducida por primera vez directamente de alemán en 1977 por la Editorial Espasa Calpe, España.

12. Cabe destacar que para Kant la naturaleza también es un producto de la conciencia, es decir, reconocemos en la naturaleza únicamente lo que antes nosotros mismos hemos puesto en ella. Y este reconocimiento está mediado y limitado por los sentidos, y no se relaciona con la moral.

13. Kant, Immanuel. Crítica del Juicio. Editorial Espasa Calpe, Madrid, 1977, pág. 49.

14. Kant, Immanuel. Crítica del Juicio. Editorial Espasa Calpe, Madrid, 1977. Pág. 373. 